\title{
MIDTERM RESULTS AFTER AORTIC VALVE REPLACEMENT WITH FREEHAND STENTLESS XENOGRAFTS: A COMPARISON OF THREE PROSTHESES
}

Giovanni Battista Luciani, MD

Paolo Bertolini, MD

Barbara Vecchi, MD

Alessandro Mazzucco, MD
Objective: The ideal substitute for the diseased aortic valve is yet to be found. For the assessment and comparison of the midterm results after aortic valve replacement with three different types of freehand stentless xenografts, all patients who underwent the operation between October 1992 and April 1997 were reviewed. Methods: Of 231 patients undergoing aortic valve replacement, 106 patients (group 1) were given the Biocor PSB (Biocor Industria e Pesquisa Ltda, Belo Horizonte, MG, Brazil); 76 patients (group 2) were given the Toronto SPV (St. Jude Medical, Inc., St. Paul, Minn.), and 49 patients (group 3) were given the O'Brien-Angell valve (Bravo Cardiovascular model 300, Cryolife, Inc., Marietta, Ga.). The first two xenografts require inflow and outflow suturelines; the third xenograft needs a single-sutureline implantation. Mean age $(70 \pm 6$ years; $70 \pm 7$ years; $72 \pm 9$ years; $p=0.6$ ), prevalence of male sex (56 patients, 53\%; 37 patients, 49\%; 22 patients, 45\%; $p=0.7$ ), of aortic stenosis (72 patients, $68 \%$; 54 patients, 71\%; 37 patients, 73\%; $p=0.6$ ), and need for associated procedures (51 patients, 48\%; 30 patients, 40\%; 21 patients, $43 \% ; p=0.1$ ) were comparable among groups. Mean aortic crossclamp time was shorter in group 3 (96 \pm 24 minutes; $100 \pm 23$ minutes; $88 \pm 25$ minutes; $p=0.01$ ). Results: Early deaths were 3 of $106(3 \%)$ in group 1, 2 of $76(3 \%)$ in group 2, and 2 of $49(4 \%)$ in group 3. Follow-up of survivors ranged from 1 to 54 months (mean $32 \pm 13$ months). Survival at 4 years was $90 \% \pm 3 \%$ in group $1,95 \% \pm 3 \%$ in group $2,85 \% \pm 8 \%$ in group $3(p=0.3)$. At 4 years, freedom from valve-related events was $95 \% \pm 6 \%, 100 \%, 70 \% \pm 8 \%(p=0.004)$, while freedom from valve deterioration was $99 \% \pm 1 \%, 100 \%, 73 \% \pm 8 \%$ $(p=0.001)$, in group 1,2 , and 3 , respectively $(p=0.001)$. At follow-up, reintervention on the xenograft was necessary in one patient (endocarditis) in group 1, none in group 2, and six in group 3 (technical cause, group 3; valve tear, group 2; pannus, group 1). Regression analysis showed O'BrienAngell type of xenograft to be predictive of valve-related events $(p=0.02)$, valve deterioration $(p=0.001)$, and reoperation $(p=0.001)$ during follow-up. Conclusions: Midterm survival after stentless aortic valve replacement is good with all three xenografts. Freedom from valve-related events, valve deterioration, and reoperation are excellent with the Biocor PSB or the Toronto SPV stentless valves but less satisfactory with the O'Brien-Angell valve. (J Thorac Cardiovasc Surg 1998;115:1287-97)
$\mathrm{T}_{\mathrm{D}}^{\mathrm{h}}$ he ideal aortic valve substitute is yet to be found. Despite the low valve-related morbidity associated with stented porcine xenografts, the evidence

From the Division of Cardiac Surgery, University of Verona, Verona, Italy.

Read at the Twenty-third Annual Meeting of The Western Thoracic Surgical Association, Napa, Calif., June 25-28, 1997.

Received for publication July 8, 1997; revisions requested Oct. 10, 1997; revisions received Dec. 1, 1997; accepted for publication Dec. 30, 1997. of limited durability and suboptimal hemodynamics, even with the latest generation of bioprostheses, continues to represent major shortcomings. ${ }^{1-4}$

Address for reprints: Giovanni Battista Luciani, MD, Division of Cardiac Surgery, University of Verona, O. C. M. Piazzale Stefani 1, Verona, 37126, Italy.

Copyright (C) 1998 by Mosby, Inc.

$0022-5223 / 98 \$ 5.00+0 \quad \mathbf{1 2 / 6 / 8 8 0 1 2}$ 
Table I. Demographic data

\begin{tabular}{lcccc}
\hline & $\begin{array}{c}\text { Group } 1 \\
\text { (Biocor PSB) }\end{array}$ & $\begin{array}{c}\text { Group } 2 \\
\text { (Toronto SPV) }\end{array}$ & $\begin{array}{c}\text { Group 3 } \\
\text { (O'Brien-Angell) }\end{array}$ & $p$ Value \\
\hline$n$ & 106 & 76 & 49 & $72 \pm 8$ \\
Age (yr) & $70 \pm 6$ & $70 \pm 7$ & $22 / 27(45 \%)$ & $0.24^{*}$ \\
Gender (M/F) & $56 / 50(53 \%)$ & $37 / 39(49 \%)$ & $3.0 \pm 0.6$ & $0.67 \dagger$ \\
Mean NYHA class & $2.9 \pm 0.6$ & $2.9 \pm 0.7$ & $1.71 \pm 0.16$ & $0.88^{*}$ \\
BSA (m ${ }^{2}$ ) & $1.75 \pm 0.18$ & $1.75 \pm 0.18$ & 37 & $0.39 \dagger$ \\
AS (no. of patients) & 72 & 54 & 2 & $0.74 \dagger$ \\
AI (no. of patients) & 12 & 8 & 9 & $0.46 \dagger$ \\
AS/AI (no. of patients) & 19 & 13 & 1 & $0.70 \dagger$ \\
Redo AVR & 3 & 1 & $0.89 \dagger$ \\
\hline
\end{tabular}

$B S A$, Body surface area; $A S$, aortic stenosis; $A I$, aortic insufficiency; $A V R$, aortic valve replacement.

*One-way ANOVA; $†$ Pearson's $\chi^{2}$.

The observation of more durable results and favorable hemodynamic performance obtained with freehand when compared with stent-mounted aortic homografts ${ }^{5}$ has prompted a revived interest in a new generation of stentless porcine xenografts. ${ }^{6}$ Because of the structural similarity with freehand homograft valves, stentless prostheses adapt to the aortic root to reproduce the anatomy of the native aortic valve. The expectation is that by offering optimal hemodynamic performance and reducing the mechanical stress on the valve leaflets, degeneration of the bioprosthesis may be slowed and stentless xenografts may prove more durable than commonly used stented valves. ${ }^{6}$

Although only the test of time over 10 years after implantation will prove the value of this hypothesis, initial experience with stentless aortic xenografts already allows identification of some of the limitations with the currently available valve models. We present our clinical experience with aortic valve replacement (AVR) with three types of freehand stentless xenografts in 231 patients.

\section{Patients and methods}

Patient population. In October 1992, a clinical program of AVR with stentless porcine xenografts was started at the University of Verona. Selection criteria for enrollment in the study were the same applied to patients who received stented porcine xenografts, including (1) age older than 65 years, (2) contraindications to oral warfarin therapy, and (3) deliberate request of a biologic valve by the patient. In the latter two cases, a choice among an aortic homograft, a pulmonary homograft, and a porcine xenograft was offered to the patient. Children less than 18 years of age were excluded from the study because they were only offered a pulmonary autograft. When the decision to replace the aortic valve with a xenograft was reached, the ultimate choice between stented (Hancock
II, Medtronic, Inc., Minneapolis, Minn.) or freehand stentless valve was left to the surgeon.

Three different models of stentless porcine bioprostheses were used for the study, including (1) group 1: the Biocor PSB valve (Biocor Industria e Pesquisa Ltda, Belo Horizonte, MG, Brazil); (2) group 2: the Toronto SPV valve (St. Jude Medical, Inc., St. Paul, Minn.); and (3) group 3: the O'Brien-Angell valve (Bravo Cardiovascular model 300, Cryolife, Inc., Marietta, Ga.). The choice of the type of stentless valve to implant was done by the surgeon in a nonrandom fashion.

Two hundred thirty-one consecutive patients were included in the study between October 1992 and April 1997. Retrospective review of the patient population showed a predominantly elderly group of subjects with similar demographic variables among the three groups (Table I). Primary indication for AVR was aortic stenosis in all groups, less commonly regurgitation or a combination of the two. Only five patients had prosthetic valve dysfunction as indication for stentless AVR (Table I).

Xenograft valve structure and operative technique. The Biocor PSB valve is a composite valve made of selected individual porcine cusps, avoiding leaflets with muscular bands. The leaflets are tanned with glutaraldehyde under no pressure and sutured to a conduit of bovine pericardium. The conduit is then scalloped to mimic the natural aortic valve.

The Toronto SPV valve is made of a single porcine root that is fixed under low pressure with glutaraldehyde. The coronary sinuses are trimmed down to 1.5 to $2.0 \mathrm{~mm}$ to form the base of the leaflets, and the outside wall is thinned and covered with a Dacron cloth.

The O'Brien-Angell valve is a composite valve made of three noncoronary leaflets from three different porcine valves, already fixed with glutaraldehyde under near zero pressure. The leaflets are sutured together along the free edges of the aortic wall at the leaflet commissures.

The technique of implantation adopted for the Biocor PSB and Toronto SPV valve consisted of sizing at the sinotubular junction and grafting with an inflow (with interrupted 4-0 multifilament polyester sutures or continuous running 4-0 polypropylene sutures) and an outflow sutureline with running 4-0 polypropylene sutures. ${ }^{6}$ Implantation of the O'Brien-Angell valve included sizing at 
Table II. Operative data

\begin{tabular}{lcccc}
\hline & $\begin{array}{c}\text { Group 1 } \\
\text { (Biocor PSB) }\end{array}$ & $\begin{array}{c}\text { Group 2 } \\
\text { (Toronto SPV) }\end{array}$ & $\begin{array}{c}\text { Group 3 } \\
\text { (O'Brien-Angell) }\end{array}$ & $p$ Value \\
\hline$n$ & 106 & 76 & 49 & $88 \pm 25$ \\
Crossclamp time (min) & $96 \pm 24$ & $100 \pm 23$ & $119 \pm 34$ & $0.01^{*}$ \\
Bypass time (min) & $129 \pm 31$ & $133 \pm 40$ & $24 \pm 2,25$ & $0.03^{*}$ \\
Valve size (mm): mean, median & $24 \pm 2,23$ & $25 \pm 2,25$ & 20 & $0.12^{*}$ \\
Associated procedures (no. of patients) & 51 & 30 & 15 & $0.15 \dagger$ \\
CABG (no. of patients) & 30 & $41 / 4$ & $2 / 1$ & $0.39 \dagger$ \\
MVR/repair (no. of patients) & $11 / 4$ & 3 & 1 & $0.39 \dagger$ \\
Ascending aorta replacement (no. of patients) & 4 & 2 & 1 & $0.35 \dagger$ \\
Carotid endoarterectomy (no. of patients) & 2 & $0.84 \dagger$ \\
\hline
\end{tabular}

$C A B G$, Coronary artery bypass graft; $M V R$, mitral valve replacement.

* One-way ANOVA.

$\dagger$ Pearson's $\chi^{2}$

the level of the aortic anulus, with selection of a prosthesis one size larger than measured, and grafting in a supraannular, infracoronary position with running 3-0 polypropylene sutures. ${ }^{7}$

Shorter aortic crossclamp and cardiopulmonary bypass times were recorded in group 3 patients as expected because of the simplified implantation technique of the O'Brien-Angell xenograft (Table II). The need for associated procedures was relatively common in our series and consisted primarily of myocardial revascularization operations (Table II). When a concomitant procedure on the mitral valve was required, an attempt at repair was done whenever feasible. In case of replacement, a stented porcine bioprosthesis was always implanted. Replacement of the ascending aorta in patients with poststenotic dilatation ( $\geq 5 \mathrm{~cm}$ diameter) and unilateral or bilateral carotid thromboendoarterectomy accounted for the remaining associated procedures. Analysis of the number and type of associated operations performed did not reveal any difference among patient groups (Table II).

Follow-up methods. All patients were seen at 1, 6, and 12 months after the operation and on a yearly basis thereafter. Echocardiographic examination was performed at discharge, at 6 months, and on a yearly basis thereafter. Follow-up of survivors was last collected between April 30 and May 15, 1997. Only two (0.9\%) patients could not be reached.

Statistical analysis. Continuous variables were expressed as means \pm standard deviations, and discrete variables were expressed as percentage. Comparison among groups was with the one-way analysis of variance for continuous variables and Pearson's $\chi^{2}$ test for discrete ones. Actuarial life table estimates were constructed with the Kaplan-Meier method and comparison among curves was carried out with the log-rank test. Multivariable analysis was performed with the Cox proportional hazards method $^{8}$ to identify risk factors for time-related occurrence of events after AVR, including (1) any event, (2) valve-related events, (3) reoperation, and (4) structural and nonstructural valve deterioration. Definitions of these events were established according to the recently recommended guidelines. ${ }^{9}$ The variables entered in the analysis are listed in the appendix.

\section{Results}

Survival. There were seven (3\%) early deaths ( $<30$ days or before hospital discharge). Three (3\%) patients in group 1 died of low output syndrome ${ }^{2}$ and cerebrovascular accident, ${ }^{1}$ respectively, 5, 15, and 45 days after the operation. Two (3\%) early deaths in group 2 were due to low output syndrome and cerebrovascular accident, 1 and 28 days after operation. Finally, two (4\%) patients in group 3 died early of cerebrovascular accident and of sepsis, 30 and 50 days after AVR. Follow-up of survivors ranged from 1 to 54 months (mean $32 \pm 13$ months). There was a total of nine $(4 \%)$ late deaths during the study period. Six $(6 \%)$ patients in group 1 died of malignancy $(n=2)$, cardiac cause $(n=2)$, pneumonia $(n=1)$, and sudden death $(n=1)$. Only one (1\%) patient in group 2 died of malignancy. Two (4\%) patients in group 3 died of malignancy and sudden death. Actuarial 1- and 4-year survival was comparable in the three groups as shown in Fig. 1.

Complications. A total of five (2\%) patients had early complications, including two patients in group 3 requiring reoperation. Three patients, one in each group, had early morbid events including gastrointestinal hemorrhage in a patient who was receiving only oral antiplatelet therapy (group 1), low output syndrome necessitating intraaortic balloon counterpulsation for 3 days (group 2), and postoperative acute myocardial infarction (group 3 ). Overall late (i.e., after discharge or 30 days) complications were recorded in 15 (7\%) patients during follow-up. In six patients (two in group 1 and four in group 3 ) morbid events led to late reoperation, as will be described. The remaining nine patients who had late compli- 


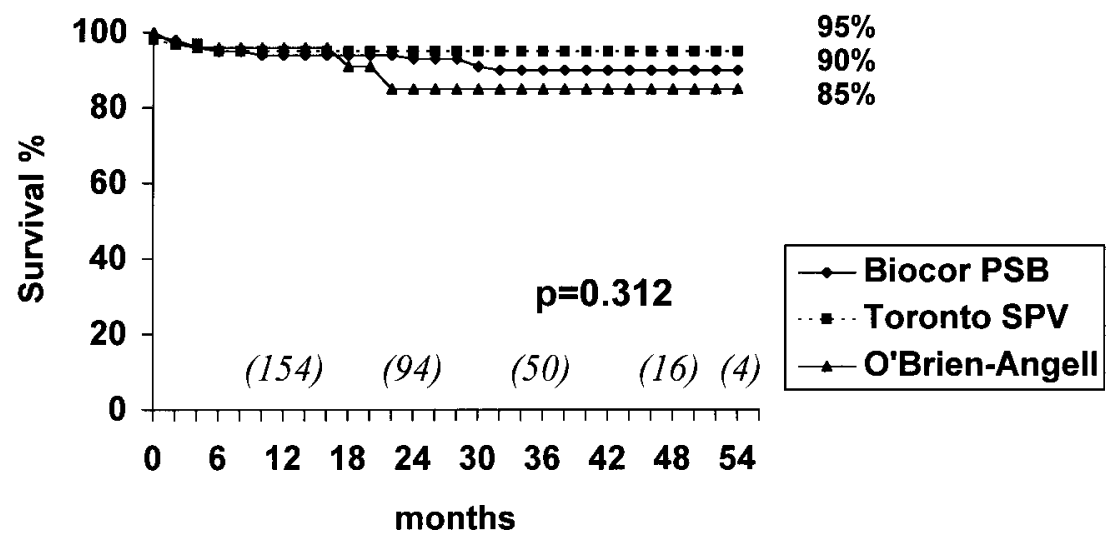

Fig. 1. Actuarial survival after AVR with three different models of freehand stentless aortic xenografts.

cations were seven (7\%) patients in group 1 and two $(3 \%)$ patients in group 2 . In group 1 two patients had a cerebrovascular complication; three patients were diagnosed with cancer; one patient had prosthetic valve endocarditis; and one patient had complete atrioventricular block that necessitated permanent pacing. Complications in group 2 consisted of recurrent episodes of pulmonary edema in two patients with left ventricular failure. Overall eventfree survival was significantly better in groups 1 and 2 than in group 3, with 1- and 4-year estimates of $93 \% \pm 2 \%$ and $82 \% \pm 4 \%, 95 \% \pm 3 \%$ and $95 \% \pm$ $3 \%, 74 \% \pm 7 \%$ and $58 \% \pm 9 \%$, respectively $(p=$ $0.01)$.

Valve-related events. When only valve-related adverse events, including valve-related death, were considered, a significant difference was noted between group 1 and 2 patients, who had similar freedom from events, and group 3, who more commonly experienced valve-related complications (Fig. 2). Mulitvariable analysis disclosed O'Brien-Angell type of xenograft and female gender as incremental risk factors for a valve-related adverse event during the study period (Table III).

Only one patient (group 1) in the entire series had early bleeding complications that could be connected with postoperative oral antiplatelet therapy. At follow-up, $96 \%$ of survivors were free from oral warfarin therapy.

Two patients in group 1 had cerebral embolism, 1 and 2 years respectively after AVR. None of the patients had undergone concomitant carotid endoarterectomy or had been previously diagnosed with cerebrovascular pathologic evidence; thus the gene- sis of the embolic episodes was classified as valve related.

Only in one patient in group 1 did Streptococcus bovis prosthetic valve endocarditis develop 3 years after operation. The patient underwent replacement of the Biocor xenograft valve with an aortic homograft and had an uneventful recovery, with no replase of infection 10 months after homograft root replacement.

Valve deterioration. Structural valve deterioration was encountered only in two (4\%) patients in group 3 during follow-up. Both women had moderate to severe periprosthetic regurgitation, confirmed by angiography, respectively 5 and 10 months after AVR, which led to reoperation.

Nonstructural valve deterioration was recognized in one $(1 \%)$ patient in group 1 and in eight $(16 \%)$ patients in group 3. The patient with Biocor PSB AVR was diagnosed with a peak transprosthetic pressure gradient of $50 \mathrm{~mm} \mathrm{Hg} 6$ months after operation, which remained unchanged at follow-up. Of the eight patients with O'Brien-Angell xenografts who had nonstructural valve deterioration, four underwent reoperation (two early and two late) because of the severity of prosthetic valve obstruction and/or worsening symptoms. The remaining four patients have peak pressure gradients between 52 and $65 \mathrm{~mm} \mathrm{Hg}$, which has shown slow progression at follow-up, and are currently asymptomatic.

Actuarial freedom from valve deterioration for any cause was significantly lower in patients in group 3 (Fig. 3). Multivariable analysis identified O'BrienAngell type of valve and female gender as incremental risk factors for valve deterioration during follow-up (Table IV). 


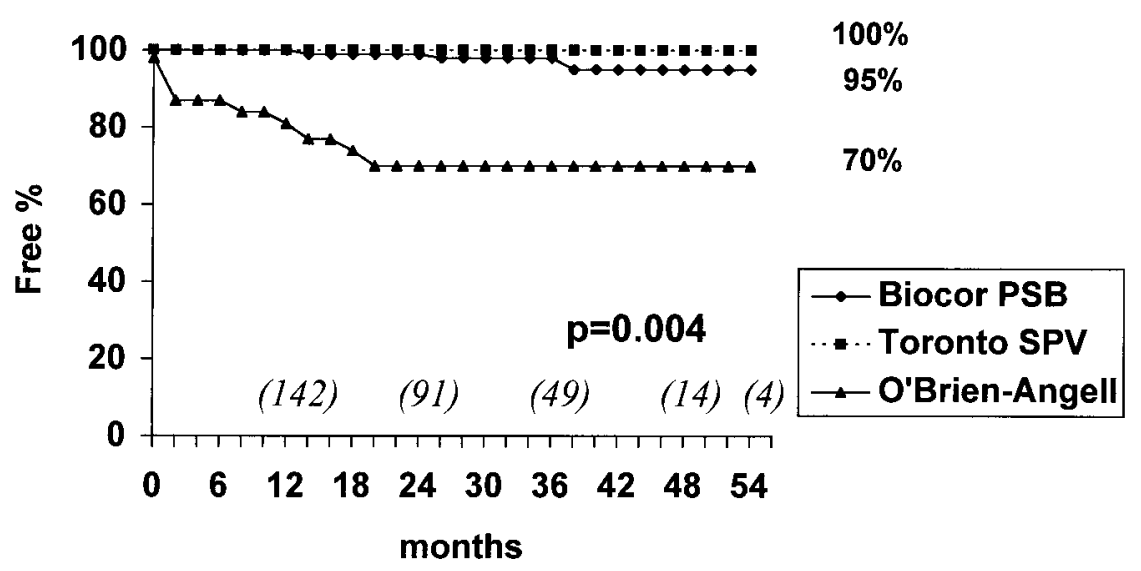

Fig. 2. Actuarial freedom from valve-related death and morbidity after AVR with three different models of freehand stentless aortic xenografts.

Reoperation. There were nine reoperations during follow-up. Three (3\%) patients in group 1 required reintervention, which was unrelated to the valve in two patients. Third-degree atrioventricular block developed in one patient 2 years after AVR, and transvenous pacemaker insertion was required. A second patient required myocardial revascularization 1 year after AVR because of left main coronary ostium stenosis. At reoperation, inspection of the Biocor PSB xenograft showed an intact valve and no anatomic relation with the obstruction of the coronary ostium. The third patient underwent homograft replacement of the stentless valve because of endocarditis, as reported earlier.

Six $(12 \%)$ reoperations were necessary in group 3 , all because of valve dysfunction. This was identified as structural in two patients with periprosthetic regurgitation. At reoperation, a tear of the porcine aortic wall support of the O'Brien-Angell xenograft was identified in both patients. In one woman the xenograft had to be replaced with a stented xenograft; in the other woman, because of the limited extension of the tear, the stentless xenograft could be reanchored to the native aortic wall. The remaining four patients underwent reoperation for nonstructural deterioration, which had manifested with prosthetic valve obstruction $(n=3)$ or regurgitation $(n=1)$. The cause of the dysfunction was possibly technical in three cases, resulting in either inappropriate sizing or incorrect supraanular positioning of the graft; the dysfunction was related to early pannus ingrowth in one. ${ }^{10}$ All patients survived replacement of the stentless bioprosthesis with a stented one, which had to be
Table III. Cox regression analysis: valve-related events

\begin{tabular}{lcrrr}
\hline & & \multicolumn{2}{c}{$95 \%$} \\
Confidence & \multicolumn{1}{c}{$\begin{array}{c}p \\
\text { limits }\end{array}$} & Value \\
\hline O'Brien-Angell valve & 2.46 & 1.12 & 5.42 & 0.03 \\
Female gender & 4.26 & 0.88 & 20.58 & 0.07 \\
\hline
\end{tabular}

The hazard ratio associated with the O'Brien-Angell valve describes the risk of the event associated with the O'Brien-Angell valve versus the risk associated with both other valves combined; $p$ values are referred to the coefficients relative to each single covariate.

associated to a Nicks aortic anulus enlargement procedure in one patient because of extensive scarring of the aortic root. Actuarial freedom from reoperation on the prosthesis was significantly lower in group 3 (Fig. 4). Regression analysis demonstrated O'BrienAngell type of valve and female gender to be incremental risk factors for reintervention on the xenograft (Table V).

Functional outcome. Follow-up clinical status showed significant improvement compared with preoperative condition in terms of mean New York Heart Association functional class in all groups $(2.9 \pm 0.6$ vs $1.4 \pm 0.7, p=0.01$, group $1 ; 2.9 \pm 0.7$ vs $1.1 \pm 0.4,0.01$, group $2 ; 3.0 \pm 0.6$ vs $1.4 \pm 0.8, p=$ 0.01 , group 3 ). No difference in terms of clinical outcome could be identified among the three groups.

When functional performance of the xenograft was analyzed by means of transthoracic echocardiography, no instance of prosthetic valve regurgitation greater than mild was detected in any of the patients, excluding those undergoing reoperation 


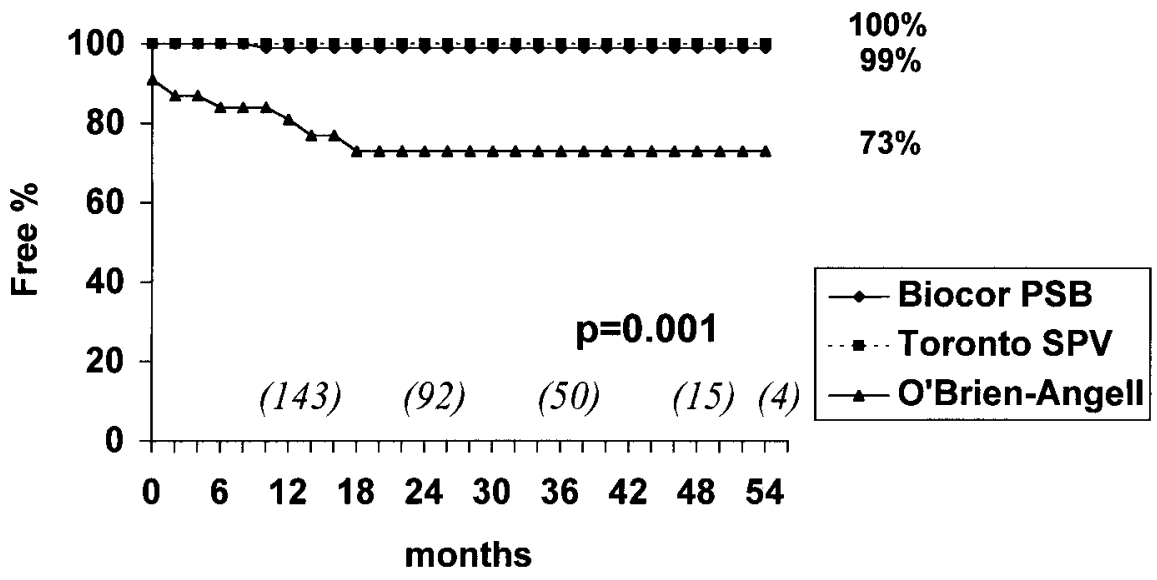

Fig. 3. Actuarial freedom from structural and nonstructural graft deterioration after AVR with three different models of freehand stentless aortic xenografts.

Table IV. Cox regression analysis: structural and nonstructural valve deterioration

\begin{tabular}{lcccc}
\hline \multicolumn{1}{c}{ Variable } & Hazard ratio & $\begin{array}{c}95 \% \\
\text { Confidence } \\
\text { limits }\end{array}$ & $\begin{array}{c}p \\
\text { Value }\end{array}$ \\
\hline O'Brien-Angell valve & 7.29 & 2.36 & 22.56 & 0.001 \\
Female gender & 9.47 & 1.20 & 74.93 & 0.03 \\
\hline
\end{tabular}

The hazard ratio associated with the O'Brien-Angell valve describes the risk of the event associated with the O'Brien-Angell valve versus the risk associated with both other valves combined; $p$ values are referred to the coefficients relative to each single covariate.

for valve deterioration. On the contrary, different results were found in terms of peak transprosthetic pressure gradients at 6-month follow-up investigation among patient groups (Table VI). Although peak pressure gradients were higher the smaller the diameter of the valve in each group, as might be expected, the values were also higher for the same valve size in patients in group 3 when compared with patients in both group 1 and group 2. Limited sampling in the very small and in the very large valve size categories may account for $p$ values not reaching statistical significance (Table VI).

\section{Discussion}

The concept of AVR with a stentless porcine xenograft began with the pioneering work of Binet and associates $^{11}$ and O'Brien and associates ${ }^{12}$ in the mid1960s. The recent revival of attention toward stentless valves moved primarily from the observation of optimal hemodynamic performance and longer durability of freehand when compared with stent-mounted aortic homografts. ${ }^{5}$ Because mechanical stress imposed on the leaflets of a stented porcine bioprosthesis has been identified as the major cause of late degeneration, ${ }^{13-15}$ it was hypothesized that the limitations even with the latest models of stent-mounted porcine valves ${ }^{1-3}$ could be overcome with stentless xenografts. ${ }^{6}$ Preliminary reports of ideal hemodynamic function, absolutely comparable with aortic homografts ${ }^{16-18}$ and the advantage of ready availability in all sizes promoted a rapid diffusion of a large variety of xenograft models into the market, ${ }^{6,18-21}$ possibly delaying the collection of significant data to test the durability of these valves.

Unique to the present study is the simultaneous experience with three types of stentless valves in a single institution. A retrospective comparison of clinical and functional results is thus possible.

Replacement of the aortic valve with a stentless xenograft is a more demanding surgical procedure and will result in longer periods of myocardial ischemia when compared with AVR with stented bioprostheses. ${ }^{16,17,20}$ In addition, freehand aortic xenografts, which are implanted with inflow and outflow suture lines, will require longer duration of ischemia compared with simplified-implant xenografts, where a single suture line is needed. ${ }^{22}$ It is apparent from the data herein that longer aortic crossclamp time does not adversely affect operative survival, which was absolutely comparable to agematched populations receiving stented bioprostheses, ${ }^{1-3}$ as previously shown by others. ${ }^{19-23}$ This consideration holds true in spite of the high prevalence of associated disease conditions requiring concomitant surgical management and thus increasing the operative risk, as evident in our patient population. It is noteworthy that cerebrovascular accident was as 


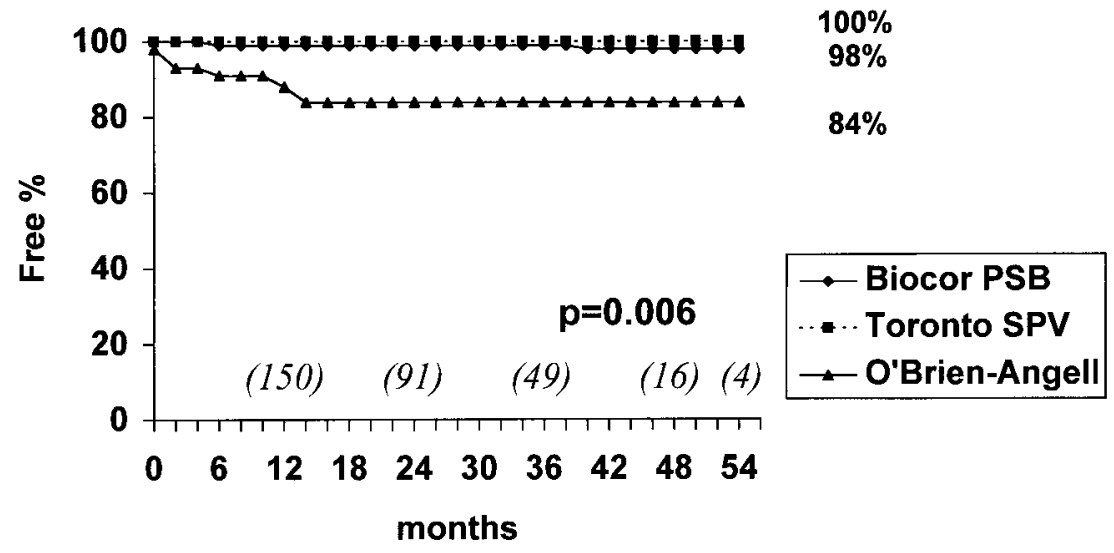

Fig. 4. Actuarial freedom from reoperation after AVR with three different models of freehand stentless aortic xenografts.

common a cause of early death as circulatory failure, possibly because of the advanced mean age of the patients and the prevalence of vascular disorders. Midterm survival after stentless xenograft AVR in the elderly was also satisfactory and in agreement with previously published series with younger patients. $^{23}$ As observed with operative survival, no difference in terms of midterm survival could be observed among groups of patients who received the three different prosthetic devices. Advanced age could once again account for malignancy being the leading cause of late death. It would thus be unjustified to reject use of Biocor PSB, Toronto SPV, or O'Brien-Angell stentless xenografts on the basis of a presumptive higher risk of operative or late death.

Prevalence of early and late morbidity was overall low, not exceeding $9 \%$ of the entire patient population. Complications unrelated to the insertion or presence of the aortic xenograft were comparable in the three subgroups and commonly caused by malignancy or congestive heart failure. When freedom from all, including valve-related, events was analyzed, this seemed satisfactory both in patients who received Biocor PSB and Toronto SPV valves and comparable with estimates presented after AVR with stented bioprostheses. ${ }^{1-3}$ However, a significantly poorer outcome was already evident 4 years after implantation of O'Brien-Angell xenografts. The demonstration that the difference, in terms of event-free survival among patient groups, was solely due to the prevalence of valve-related complications is evident from Fig. 2. Accordingly, logistic regression analysis disclosed the latter type of xenograft as an incremental risk factor for valve-related events during follow-up. Further assessment showed that prevalence of hemorrhage, thromboembolism, and prosthetic valve endocarditis could not account for the notable difference among the three types of xenografts. Indeed, these complications were overall quite uncommon, and no difference among groups could be disclosed. On the contrary, occurrence of valve deterioration, rarely or never encountered respectively after Biocor PSB or Toronto SPV implantation, was prevalent in patients who received O'Brien-Angell valves. Because the test of time for a porcine bioprosthesis is durability 8 to 10 years after implantation, ${ }^{1,2,3,6}$ an actuarial freedom from valve deterioration of $73 \%$ at 4 years for the latter xenograft represents a disappointingly low figure (Fig. 3). Once again, the use of the O'Brien-Angell prosthesis was isolated as a risk factor for valve deterioration after stentless AVR. To date this complication has led 6 of 10 patients in group 3 to reoperation. Despite a slow tendency to progress, reintervention in the near future on the remaining four patients with moderate prosthetic valve obstruction cannot be excluded.

Because of the relatively short period of observation, reoperation on the stentless xenografts was generally uncommon and never in relation with calcific degeneration, the well-recognized leading cause of late failure of stented bioprostheses. ${ }^{24}$ Aside from a case of replacement of Biocor PSB xenograft for prosthetic valve endocarditis, reoperation was limited to patients who had received the O'Brien-Angell bioprosthesis, making implantation of this device an incremental risk factor for reintervention during the observation period. Structural failure consisting in a tear of the aortic wall support of the O'Brien-Angell composite xenograft was ob- 
Table V. Cox regression analysis: reoperation

\begin{tabular}{lcccc}
\hline \multicolumn{1}{c}{ Variable } & Hazard ratio & $\begin{array}{c}95 \% \\
\text { Confidence } \\
\text { limits }\end{array}$ & $\begin{array}{c}p \\
\text { Value }\end{array}$ \\
\hline O’Brien-Angell valve & 7.29 & 2.39 & 22.83 & 0.001 \\
Female gender & 9.18 & 1.15 & 73.30 & 0.04
\end{tabular}

The hazard ratio associated with the O'Brien-Angell valve describes the risk of the event associated with the O'Brien-Angell valve versus the risk associated with both other valves combined; $p$ values are referred to the coefficients relative to each single covariate.

served in our series. ${ }^{10}$ Similar complications were already reported by Hvass and associates ${ }^{22}$ and represent elements of concern for a device that is anchored to the aortic root by means of a single suture line. Even though replacement of the xenograft may not always be needed, reintervention must be undertaken whenever a perivalvular regurgitation is observed to verify stability of the prosthesis. Among causes of nonstructural valve deterioration, overgrowth of fibrous tissue was also noted early after AVR with stentless xenografts, ${ }^{10}$ as previously described with stented porcine bioprostheses. ${ }^{25}$ The most common cause of nonstructural failure of O'Brien-Angell valves leading to reintervention was, however, transprosthetic obstruction. By virtue of its design, this xenograft needs to be implanted in a subcoronary, but supraannular position, to avoid protrusion of the porcine aortic wall support into the left ventricular outflow tract. Despite the apparent simplicity of this concept, technical realization may not always be as immediate. A variety of anatomic and pathologic conditions involving the aortic root will adversely influence the ability to correctly position the bioprosthesis. Most important, a xenograft that is implanted with a single suture line is more flexible than a two-suture line stentless valve and will be more easily distorted when anchored to an asymmetric aortic root. This may cause obstruction because of the protrusion of the aortic wall into the aortic orifice, regurgitation because of the crowding of the leaflets, or both. Our experience with over 200 implantations of freehand stentless xenografts suggests that technical mishaps are not infrequent with the O'Brien-Angell valve, although these are negligible with either the Biocor PSB and the Toronto SPV valve. The present findings are at variance with data reported by O'Brien and associates ${ }^{19}$ but faithfully reproduce the series by Hvass and associates, ${ }^{22}$ who described unsatisfactory postoperative gradients (i.e., nonstructural dysfunction in the present report) in most of their first
Table VI. Six-month follow-up transaortic peak pressure gradient ( $\mathrm{mm} \mathrm{Hg}$ )

\begin{tabular}{lcccc}
\hline & $\begin{array}{c}\text { Group 1 } \\
\text { (Biocor } \\
\text { PSB) }\end{array}$ & $\begin{array}{c}\text { Group 2 } \\
\text { (Toronto } \\
\text { SPV) }\end{array}$ & $\begin{array}{c}\text { Group 3 } \\
\text { (O'Brien- } \\
\text { Angell) }\end{array}$ & $\begin{array}{c}p \\
\text { Value }\end{array}$ \\
\hline$n$ & 96 & 73 & 39 & \\
Valve size 21 & $24 \pm 15$ & $31 \pm 16$ & $34 \pm 10$ & $0.17^{*}$ \\
Valve size 23 & $19 \pm 11$ & $20 \pm 9$ & $38 \pm 27$ & $0.03^{*}$ \\
Valve size 25 & $15 \pm 8$ & $17 \pm 8$ & $26 \pm 20$ & $0.06^{*}$ \\
Valve size 27 & $14 \pm 4$ & $17 \pm 7$ & $19 \pm 8$ & $0.32^{*}$ \\
Valve size 29 & $15 \pm 8$ & $10 \pm 5$ & NA & $0.44^{*}$ \\
\hline
\end{tabular}

$N A$, Not applicable.

*Pearson's $\chi^{2}$.

50 implantations, thereby confirming the existence of a steep learning curve.

On the basis of the current experience, reoperation on a failed stentless xenograft does not represent an exceedingly challenging technical task and can be performed with excellent survival (no casualties among the seven replacements of the bioprosthesis).

When the functional properties of stentless aortic xenografts are evaluated in terms of valve stenosis or regurgitation, comparison with commonly used stented bioprostheses appears extremely favorable, as evident from our clinical series, as well as others. $^{6,16}$ A wealth of data is already available that describes the optimal functional results after AVR with the Toronto SPV valve, including the documented tendency of the transprosthetic pressure gradients to decrease over time and the effective orifice area to increase over time. ${ }^{23,26}$ Resolution of the inflammatory changes of the aortic wall "excluded" by the xenograft and regression of the left ventricular hypertrophy have been implicated to account for these observations. The present experience with the Toronto SPV valve confirms that the reported results ${ }^{16,17,23,26}$ are readily reproducible. Information on hemodynamic performance of the Biocor PSB valve is instead limited to one other institution. ${ }^{21}$ Comparison with our series is unsound because of the difference in the age (mean age 36 vs 70 years) and indication to AVR (rheumatic valve disease in $64 \%$ vs senile calcific degeneration in $70 \%$ ) of the patient population, which possibly explains the poorer freedom from adverse events in the experience of others. ${ }^{21}$ On the basis of our midterm results on a mostly senescent group of patients, the Biocor PSB valve proved as dependable as the Toronto SPV xenograft both in terms of freedom from valve-related morbidity and of func- 
tional profile. On the contrary, even when cases labeled as nonstructural deterioration of the prosthesis were excluded from observation, peak pressure gradients across the O'Brien-Angell xenograft tended to be higher in each valve size (Table VI). Because this graft is implanted with a single suture line, however, decrease of the degree of obstruction cannot be expected in the future. Interpretation of these results does not differ from the explanation of cases of nonstructural deterioration. When compared with the more lengthy and complicated technique of grafting of the Biocor PSB and Toronto SPV valve, implantation of the O'Brien-Angell valve appears simple. Our work suggests that greater simplicity may translate into a less predictable early hemodynamic result.

It must be emphasized that the exact relationship between postoperative transprosthetic pressure gradients and symptoms is still undefined. In fact, all patients showed clinical improvement at follow-up that was not significantly different among the three groups.

Limitations. There are some notable limitations to our study. The present work is a retrospective analysis on a nonrandomized group of consecutive patients. Thus the issue of comparability of patients among the three groups becomes crucial. Another potential limitation may be the decision to select only elderly patients for this operation. Because of the predicted life expectancy of individuals in the seventh or eighth decade of life, the patients at risk 10 years or longer after xenograft valve replacement could decrease independently from the morbidity of the prosthesis. The use of statistical analysis to predict actual rather than actuarial events will then become necessary.

On the other hand, this experience presents some unique aspects. It is the only work that compares three different stentless aortic xenografts at a single institution. This would allow disclosure of different learning curves with different devices, if it were the case. It is a quantitatively sizable series, in that previously published reports rarely exceed 200 patients. ${ }^{16-23}$ Most significantly, it offers insight into factors that will predict occurrence of adverse events during a midterm follow-up.

\section{Conclusions}

Analysis of over 230 patients undergoing AVR with three types of freehand stentless xenografts showed that this more complex surgical procedure can be performed at a very low operative risk, comparable among the three groups of patients. Actuarial survival is also satisfactory as is freedom from lethal valve-related events. In the present experience, midterm outcome with the O'BrienAngell valve proved less satisfactory in terms of valve-related morbidity, including structural deterioration of the graft and reoperation. On the contrary, prevalence of adverse events after implantation of either the Biocor PSB and the Toronto SPV was negligible, and hemodynamic performance is optimal. Whether the difference in design of the O'Brien-Angell valve, in and of itself, can justify these results remains to be proved.

We thank Luisa Zanolla, MD, for the invaluable help in the statistical analysis of the data.

\section{REFERENCES}

1. David TE, Armstrong S, Sun Z. The Hancock II bioprosthesis at ten years. Ann Thorac Surg 1995:60;S229-34.

2. Bortolotti U, Milano A, Mossuto E, Mazzaro E, Thiene G, Casarotto D. Porcine valve durability: a comparison between Hancock standard and Hancock II bioprostheses. Ann Thorac Surg 1995:60;S216-20.

3. Fann JI, Miller DC, Moore KA, et al. Twenty-year clinical experience with porcine bioprostheses. Ann Thorac Surg 1996;62:1301-12.

4. Cosgrove DM, Lytle BW, Gill CC, et al. In vivo hemodynamic comparison of porcine and pericardial valves. $\mathrm{J}$ Thorac Cardiovasc Surg 1985;89:358-68.

5. Angell WW, Angell JD, Oury JH, Lamberti JJ, Grehl TM. Long-term follow-up of viable frozen aortic homografts: a viable homograft valve bank. J Thorac Cardiovasc Surg 1987;93:815-22.

6. David TE, Pollick C, Bos J. Aortic valve replacement with stentless porcine aortic bioprosthesis. J Thorac Cardiovasc Surg 1990;99:113-8.

7. O'Brien MF. The Cryolife-O'Brien composite aortic stentless xenograft: surgical technique of implantation. Ann Thorac Surg 1995;60:S410-3

8. Cox DR. Regression models and life tables. J R Stat Soc B 1972;34:187-220.

9. Edmunds LH Jr, Clarke RE, Cohn LH, Grunkemeier GL, Miller DC, Weisel RD. Guidelines for reporting mortality and morbidity after cardiac valvular operations. J Thorac Cardiovasc Surg 1996;112:708-11.

10. Luciani GB, Bertolini P, Mazzucco A. Early failure of freehand stentless aortic xenograft valves. J Thorac Cardiovasc Surg 1997;113:1109-10.

11. Binet JP, Duran CG, Carpentier A, Langlois J. Heterologous aortic valve transplantation. Lancet 1965;2:1275.

12. O'Brien MF, Neilson GH, Galea EG, et al. Heterograft valves: an analysis of clinical results of valve replacement. Circulation 1970;16,17(Suppl):II16-9.

13. Thurbrikar M, Deck JD, Aouad J, Nolan SP. Role of mechanical stress in calcification of aortic bioprosthetic valves. J Thorac Cardiovasc Surg 1983;86:115-25.

14. Broom ND. Fatigue-induced damage in glutaraldehyde-pre- 
served heart valve tissue. J Thorac Cardiovasc Surg 1978;76: 202-11.

15. Pomar JL, Bosch X, Chaitman BR, Pelletier C, Grondin CM. Late tears in leaflets of porcine bioprostheses in adults. Ann Thorac Surg 1984;37:78-83.

16. Jin XY, Gibson DK, Yacoub MH, Pepper JR. Perioperative assessment of aortic homograft, Toronto stentless valve, and stented valve in the aortic position. Ann Thorac Surg 1995; 60:S395-401.

17. Gross C, Harringer W, Mair R, et al. Aortic valve replacement: Is the stentless xenograft an alternative to the homograft? Early results of a randomized study. Ann Thorac Surg 1995;60:S418-21.

18. Dossche K, Vanermen H, Wellens F, De Geest R, Degrieck I, Deloof T. Free-hand sewn allografts, stentless (Prima Edwards) and stented (CESA) porcine bioprostheses: a comparative hemodynamic study. Eur J Cardiothorac Surg 1995;9:562-6.

19. O'Brien MF. Composite stentless xenograft for aortic valve replacement: clinical evaluation of function. Ann Thorac Surg 1995;60:S406-9.

20. Westaby S, Amarasena N, Ormerod O, Amarasena GAC, Pillai R. Aortic valve replacement with the freestyle stentless xenograft. Ann Thorac Surg 1995;60:S422-7.

21. Vrandecic M, Gontjio BF, Fantini FA, et al. Porcine stentless aortic heart valve substitute: mid-term clinical follow-up. J Cardiovasc Surg 1994;35:31-4

22. Hvass U, Chatel D, Assayag P, et al. The O'Brien-Angell stentless porcine valve: early results of 150 implants. Ann Thorac Surg 1995;60:S414-7.

23. David TE, Feindel CM, Bos J, Sun Z, Scully HE, Rakowski $\mathrm{H}$. Aortic valve replacement with a stentless porcine aortic valve: a six-year experience. J Thorac Cardiovasc Surg 1994; 108:1030-6.

24. Milano A, Bortolotti U, Talenti E, et al. Calcific degeneration as the main cause of porcine bioprosthetic valve failure. Am J Cardiol 1984;53:1066-70.

25. Bortolotti U, Gallucci V, Casarotto D, Thiene G. Fibrous tissue overgrowth on Hancock mitral xenografts: a cause of late prosthetic stenosis. Thorac Cardiovasc Surg 1979;27: 316-8.

26. Del Rizzo DF, Goldman BS, Christakis GT, David TE. Hemodynamic benefits of the Toronto stentless valve. J Thorac Cardiovasc Surg 1997;112:1431-46.

\section{Discussion}

Dr. Edward D. Verrier (Seattle, Wash.). The surgical options in the treatment of aortic valve and aortic root disease have dramatically increased in the last 10 years with the introduction of a variety of new mechanical valves, stented porcine and bovine pericardial bioprostheses, aortic homografts, pulmonary autografts, and now with the introduction of stentless aortic valves. Biomechanical analysis of the composite left ventricular outflow tract, anulus, leaflets, sinuses, and aortic wall, as well as complex computer modeling such as finite element analysis, have suggested that bioprostheses that mimic the structure, anatomy, and physiology of the normal aortic root and valve should decrease the stress, strain, and compliance changes that therefore would equate with a more durable prosthesis without requiring anticoagulation. The short-term tradeoff for the theoretic long-term benefit has to do with the technical ease of insertion of the stentless valves. These valves must be sewn in at the annular level but must also have the posts constructed usually with a second suture line.

Dr. Luciani and colleagues at Verona have implanted in a nonrandomized protocol three different stentless prostheses and have followup data of just over 3 years. Their conclusions are that the Biocor and the Toronto SP valve are similar and that both are superior to the O'BrienAngell valve in terms of valve-related events, valve degeneration, and reoperation. Operative death and projected actuarial survival from nonlethal valve-related events are similar in all three groups. This is the only study to date comparing three stentless valves in a single institution.

I have a number of concerns, however, about the study. First, the study is nonrandomized, and there certainly is a discrepancy of the size of the three groups. How were the valves selected for individual patients? Was the series concomitant or sequential, and if it was sequential, what order did you trial each valve? How many surgeons were involved, and did all the surgeons insert all the valves?

Dr. Luciani. The series is not sequential, but rather concomitant. The reason why we started with three different valves, which is a very curious experience, was that the Biocor PSB valve was the very first one to be introduced into the market in Europe and Italy, in particular. When the Toronto SPV and the O'Brien-Angell valves became available for the Italian market, we decided to test a valve that was similar to the Biocor PSB and a valve that was completely different in design. Thus most of the experience is simultaneous and not sequential. There were no specific, prospective criteria by which different models were used by the surgeons; this was left to the surgeon. Obviously this introduces an element of bias, and the fact that the study is retrospective also represents an element of bias.

Your third question was relative to the different surgeons; there were three senior surgeons who supervised or directly performed all the procedures. This factor was taken into the multivariable analysis, and it did not turn out to be associated with a different outcome in terms of functional results or valve deterioration.

Dr. Verrier. Since the follow-up is so short, it is impossible for me to believe that the conclusions are anything other than technical considerations rather than being intrinsically wrong with the O'Brien-Angell valve. In fact, in the manuscript, you note that the cause of dysfunction was "possibly technical in at least three cases, resulting in either inappropriate sizing or incorrect supraannular positioning of the graft." At the recent Seventh International Symposium on Cardiac Bioprosthesis in Barcelona where your group reported most of these data, Hvass presented 5 years of follow-up of 366 patients with the O'Brien-Angell valve. They reported two valverelated cardiac deaths, both from endocarditis, and only five reoperations, or less than $1 \%$ for nonstructural dysfunction, and none for structural dysfunction. This is in sharp contrast to the present series in which eight patients $(16 \%)$ were reoperated on for nonstructural dysfunction and two patients (4\%) for structural dysfunction. Hvass reported overall 5-year actual survival of $85 \%$ and $95 \%$ for operative survivors. Would you please comment on the 
discrepancy between your data and the data from Angell and his group?

Dr. Luciani. Dr. Hvass published a series of papers beginning with 1995, one of which, published in the European Journal of Cardiothoracic Surgery, disclosed a learning curve with the implantation of the O'BrienAngell valve device. Curiously, the same experience was not reported by Dr. O'Brien, but the person who has the largest experience with the valve is in fact Dr. Hvass in Paris, and what he found was that, in the first 50 valves implanted, the prevalence of "nonstructural" dysfunction possibly because of technical failure was quite high. The naming of the phenomenon was quite different; in fact, he had higher transprosthetic gradients and did not call these nonstructural valve failures as we did, but possibly the phenomenon was similar. The second 50 patients he analyzed had a much lower prevalence of high gradient; in the last 50 patients in whom he performed the operation (this was a series of 150 consecutive patients) he actually could achieve excellent results with minimal prevalence of this phenomenon. This event may relate to the structure of the valve that makes it more prone to technical failure. I do agree with you that our failures are possibly related to technical cause in many of the nonstructural failure groups, which apparently occurred at the moment of implantation and then revealed themselves early on after follow-up.

Dr. Verrier. My final question relates to echocardiographic follow-up in these patients. Because there are no stentless valve series in either Europe, Canada, or the United States that can answer the question of durability, which will be the key to wider acceptance of this type valve, most investigators have focused on the small increase in valve area noted over the first 3 months of implantation and the accelerated decrease in left ventricular wall mass over the first 6 months. This is a particular advantage noted by most investigators with the stentless prosthesis over the stented bioprosthesis. Can you give any data supporting the superiority of any of these three valves in terms of these very definable, objective endpoints?

Dr. Luciani. We do not have any data to support the increase in effective orifice size 3 months after implantation. We have only been following the flow across the valve in terms of peak and mean transprosthetic gradients and the degree of mass regression.

Dr. Thomas A. Pfeffer (Los Angeles, Calif.). During the past 4 years, our group in Los Angeles has implanted 93 Freestyle valves manufactured by Medtronic which, as far as I am aware, is the only stentless valve with imminent release for general use in the United States. At 4 years, approximately $78 \%$ of our patients have no aortic insuf- ficiency and about $22 \%$ have grade 1 or more aortic insufficiency, none of whom have undergone reoperation. This is essentially unchanged from our initial postoperative echocardiographic findings. My question relates somewhat to the discussion of the Ross procedure earlier this morning that had to do with the importance of valve sizing for this procedure. Didn't you comment on the technique of implantation, whether all of them were subcoronary or modified subcoronary or done as root replacements, and whether this would have any impact on the results with these valves?

Dr. Luciani. I am sorry that, because of time constraints, I could not go into the details of technique of implantations. The three valves that we used cannot be implanted in the different manners that you explained; they can only be implanted as subcoronary, freehand grafts, because they do not retain the native roots; you cannot scallop them and, alternatively, implant them as miniroot, total root, or complete freehand. Both the Biocor PSB and Toronto SPV valve need to be implanted as freehand with inflow and outflow sutures much like freehand homografts.

The O'Brien-Angell valve has a different technique of implantation, which is single suture line; in fact, it is three distinct running suture lines that anchor the valve not at annular level but at supraannular level. We believe that this specific feature of the valve, which is at one time very attractive, at the same time may be somewhat less readily apparent for the surgeon and less ready to be learned by the surgeon in terms of implantation technique.

Dr. Philip W. Wright (Honolulu, Hawaii). Are there disqualifying characteristics of systolic left ventricular function preoperatively in the selection of patients that influence the outcome or, in your practice, would influence the type of patients that you operate on?

Dr. Luciani. This is a series of nonselected patients in the way they were not prospectively randomized, so that left ventricular function was taken into consideration, and the low number of cardiac deaths compared with series that used stented procedures may explain the difference of death connected with device implantation.

\section{Appendix}

Varibles entered in the multivariable analysis with the Cox proportional hazards method as covariates included: age, gender, indication to operation, endocarditis as a cause of aortic insufficiency, presence of a bicuspid aortic valve, associated coronary artery disease, name of surgeon, need for associated procedures, size of xenograft valve, type of prosthetic device, duration of aortic crossclamp time, use of blood cardioplegia, and immediate postoperative transaortic peak pressure gradient. 